\section{SPOT DIAGNOSIS WITH NOTES ON THERAPY}

\section{Volume II}

Compiled by the editors of Medicine Illustrated. Pp. 127, with 100 illustrations. London: Harvey and Blythe Ltd. 1955. 8s. 6d.

The editors of Medicine Illustrated have produced another instalment dose of the mixture as before. A stimulating mixture it still is, though, perhaps, not so effective on your reviewer as the first dose.

The book is again in quiz form with the pictured question on one page and the written answer on the next.

Inevitably, the scope of this sort of book must be limited by the type of material which lends itself to pictorial representation. The cases presented in this volume meet this requirement with varying success. Case $5 \mathrm{I}$ meant little more than a swollen abdomen to the reviewer and he was dismayed to read, on turning the page, that he had missed a neuroblastoma of the left suprarenal gland. There are a few unfortunate mistakes. Case 78 , a girl with an obvious right facial palsy, could not, we are told, close her left eye. Case 56 portrays Horner's syndrome with enophthalmos, not exophthalmos as stated. A complaint with as intriguing a name and natural history as ainhum should surely be illustrated in the flesh rather than by the unexciting and uninformative $\mathrm{X}$-ray picture of Case 100 .

A book like this links novelty with entertainment and instruction. The novelty has gone and the editors must be more sure of the other two features before launching a third edition in this form.

H.K

\section{REFLECTIONS ON RENAL FUNCTION}

By James R. Robinson, M.D., Ph.D. Pp. I63. Oxford: Blackwell Scientific Publications. I 955. I7s. $6 \mathrm{~d}$.

This book performs two most valuable services. It explains lucidly the methods of modern renal research, collectively known as 'clearance techniques,' and it summarizes, often in provocative fashion, the most recent work in kidney physiology.

The book had its origin in a series of lectures to students reading Physiology for Part II of the Natural Sciences Tripos. Dr. Robinson's ability to put things clearly to such an audience is shown to advantage in his exposition of clearance methods; no student after reading this section could fail to have a clear idea of the principles involved. Advanced students, however, are not the only group who will profit from reading this book. Research workers will find a valuable review of many of the important lines of study engaging renal physiologists at present and some stimulating comments on gaps in our knowledge.

This book is excellent value for money and should be owned by every Department of Physiology and by every serious worker on the kidney.
A MANUAL OF PSYCHIATRY

By K. R. Stallworthy, M.B., Ch.B., D.P.n? Third edition. Pp. 324. Christchurch, Ne Zealand: N. M. Peryer Ltd. I955. Ne Zealand Price 30 s.

This is a refreshing manual which deserved forces its way into a somewhat congested field. I I scope is considerably broader than the strict clinical account provided by its contemporaries the U.K., for in addition to the traditonal treatmerfy of general psychiatry, it touches such subjects the Mind in Health, Abnormal Psychology, Mental Hygiene, Special Nursing Procedures, etc.

The chapter on legal aspects of psychiatry must be read with care, for certification, admission and discharge appear to differ in some respects to outs own conditions-in fact, the Australian States differ between themselves. One or two words hace a 'Down Under' flavour; ' guards' for example, which are used extensively in the trolley lay-outsis apparently refer to sterile towels. Insulin coma therapy receives an accurate description, although the stress is laid on phases slightly different to those stressed in our own teaching departments.

This is a bright, vigorous work which can be recommended to the new entrant to psychiatro, stressing as it does, the practical procedures so offen ignored by the more ponderous tomes. For this reason, too, it can be recommended to all P.T.S. and lecturers concerned with this subject in G.N.C. syllabus.

MATERIA MEDICA AND PHARMACOLOG FOR NURSES

\section{With Key to Calculations}

By J. S. Peel, M.P.S. Pp. 165, illustrated. Christ church: N. M. Peryer Ltd., 145-147 Worcest Street, Christchurch, C.I., New Zealand. r 955. New Zealand price 24s.

Another excellent textbook for nurses from New Zealand, this one is written by a pharmacist. The subject matter is arranged in the order in which is taught. Simple facts concerning weights and measures and percentage solutions are presented the first two chapters. In connection with thesio, problems are set to prove their usefulness nursing practice. Drugs are considered according to their actions on the various systems of the bodfy. Only those in common use which have proved to of value are mentioned. Rules for their administre. tion are included.

The author has maintained a practical approaç throughout, stimulating interest in what might easily become a dull subject in a curriculuno Excellent diagrams and illustrations support the text. Money will be well spent on this book for it will not date. Legislation mentioned is part ofoa world-wide system.

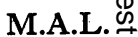

